\title{
CLOSED LOOP MODEL FOR GLUCOSE INSULIN REGULATION SYSTEM USING LABVIEW
}

\author{
${ }^{1}$ P Srinivas ${ }^{2}$ P.Durga Prasada Rao \\ ${ }^{1}$ Associate Professor, Department of EIE, VR Siddhartha Engineering College, \\ Vijayawada, India \\ Email: paruchuris_99@yahoo.com \\ ${ }^{2}$ Assistant Professor, Department of EIE, VR Siddhartha Engineering College, \\ Vijayawada, India \\ Email: dprasad_iedyahoo.com
}

\begin{abstract}
Bio-Medical Instrumentation is an expanding and demanding area in which many fields are available to explore, among which diabetes is a main segment to address. Glucose and Insulin are both interrelated terms. Glucose is a sugar which provides energy to the cells. Insulin is a hormone which supports the absorption of glucose. The Glucose-Insulin regulation model is obtained by modifying the dynamic model of stolwijk and hardy. We first develop a steady state model for normal, type-1 and type-2 diabetic persons and include dynamics to avoid the non-linearities. Using this model, a closed loop feedback system which regulates and manages the blood glucose-insulin for type-1 and type-2 diabetic persons has been designed, implemented and analyzed using LABVIEW.
\end{abstract}

\section{KEYWORDS}

Glucose, insulin, stolwijk, modeling, regulation, labview

\section{INTRODUCTION}

Diabetes is associated with various abnormalities in insulin metabolism. The sugar, starch and other food items are converted in to energy with insulin. Scientists are developing external insulin which is fed in a certain rate according to maintain the glucose levels of $60-120 \mathrm{mg} / \mathrm{dl}$. The diabetes is classified as Type- 1 and Type-2. In case of Type- 1 the controlling of insulin is very difficult. For these patients regulation of blood glucose concentration is maintained by releasing the external insulin with insulin infusion device. The insulin pump is a electro medical device which delivers insulin through narrow and flexible plastic tube that ends with a needle inserted just under the skin near the abdomen. The pump releases doses of insulin at meals and during the several periods of the day based on the values of glucose sensors. Glucose concentration may change dynamically depending on the physical activities of the human. So, the insulin requirement may vary.

In 1961, the first diabetic model developed by Bolie which consisted differential equation each for glucose and insulin [2]. A similar model was developed by Ackerman et al. for glucose insulin dynamics [3]. The interaction effects of glucose and insulin were obtained from the first two 
models. But these models failed the accountancy of distribution of insulin and glucose throughout the body. The minimal model developed by Bergman et al. (1981) had 3-compartments as lumped representation of human body [4]. This model lacked the dynamics of glucose transport and distribution in tissues and effects of glucagon, which raises the blood glucose concentration. Cobelli et al. in 1982 utilised 5- compartment models for glucose, insulin and glucagon effects each lumped into its own whole body blood pool [5]. This also included the use of threshold functions for saturation. Comparison of the peripheral versus portal route for insulin administration in closed loop glucose control was done by Cobelli and Ruggeri (1983).But they were unable to describe the glucose distribution in the body [5]. Lehmann and Deutsch in 1992 developed a nonlinear model which included a glucose sub-model was a single compartment extra cellular pool and a 2-compartment model of insulin representing plasma and active concentrations [6]. This was generalized into meal model which approximated the absorption kinetics of glucose by the blood stream. Puckett in 1992 developed a modeling study of diabetes mellitus in which a two blood pool system representing insulin and glucose concentrations which were directly affected by metabolic flux terms and exogenous signals [7]. With the help of Light foot in 1995, Puckett also demonstrated inter and intra patient variability and steady state behaviour using his models [8]. Sorensen treated glucose and insulin separately with coupling through metabolic effects utilizing threshold functions. A whole body lumped representation was also included to complete the glucose-insulin system with counter regulation. A small inclusion into this model was made by Sorenson to include meal disturbances and parameters for uncertainty analysis.

The Glucose-Insulin regulation model is obtained by modifying the dynamic model of stolwijk and hardy. An extra parameter is added for insulin infusion in the case of external insulin pump. The pumping action can be done in two ways open loop control and closed loop control. In open loop control a predetermined amount of insulin is given base on the suggestions given by the physician. The present treatment was to take a series of 2-3 daily insulin injections based on the daily/monthly glucose level measurements. In this type of treatment the insulin is discretely controlled and there is a lack of reliable continuous monitoring.

In closed loop control a feedback is taken from the body by placing the sensor which senses the glucose level in body. The output of the sensor is given to the controller and based on the error the controller pumps the required amount of insulin to the body. The closed loop control is shown in the following figure 1.

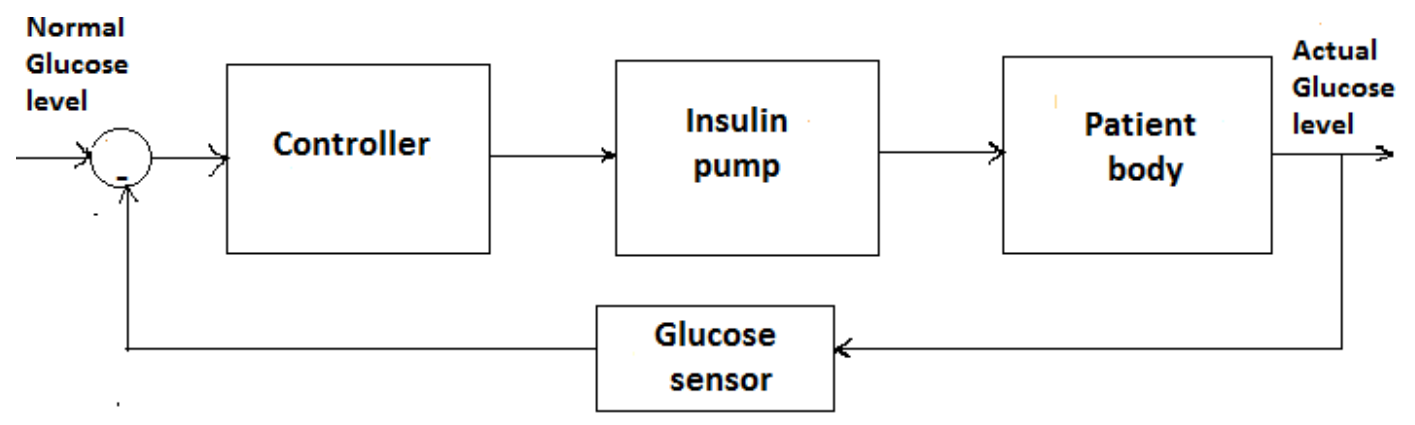

Figure1:Block diagram of Glucose Insulin regulation system

The controller is main part in the closed loop control, so, for designing the control algorithm we first develop the model of the glucose insulin kinetics of the normal person and then simulate them. The simulation results are stored in the lookup table and based on that the insulin pump 
pumps the insulin to the body. The data acquisition and control is easier in LABVIEW, hence the glucose insulin system is simulated in LABVIEW.

\section{MATHEMATICAL MODELING}

The effects of glucose and insulin regulation are observed by developing a mathematical model for the pancreatic function. One of the main functions of pancreas is to regulate the concentration of glucose in the blood by releasing an enzyme, called insulin. We developed a steady state model for glucose to obtain the equilibrium concentrations. The total volume of blood and interstitial fluids is considered as single large compartment. The complete inflow of the compartment must be balanced by the total outflow. Glucose enters into body through absorption from gastrointestinal tract or through production in liver. The parameter for input flow rate is $\mathrm{Q}$. The blood Glucose is utilized in three ways. When glucose concentration is increased above threshold limit ' $\alpha$ ', glucose is excreted by the kidneys at the rate proportional to gradient between Glucose concentration $(\mathrm{G})$ and $\alpha$. This loss due to excretion is renal loss rate, and represented as shown below

$$
\left.\begin{array}{cc}
\text { Renal loss ra:e }=\mu(G-\alpha) & G>\alpha \\
=0 & G<\alpha
\end{array}\right\}
$$

Glucose enters into cells through diffusion. Cells present in adipose tissue and muscles diffuse when stimulated by insulin. The diffusion rate depends on insulin, as shown below

$$
\text { Tissue utilization(insulin dependent) }=v G I
$$

Where I is the insulin concentration. Insulin independent cells diffuse glucose in rate which depends on extra cellular concentration gradient, the following equation represents the insulin independent tissue utilization rate.

$$
\text { 115sue uth zation }=60
$$

The mass balance equation of glucose concentration is as follows

$$
\left.\begin{array}{rlrl}
\mathrm{Q} & =3 \mathrm{G}+\mathrm{vGI} & \mathrm{G} \leqslant a \\
& =b G+v G I+\mu(\mathrm{G}-a) & G>a
\end{array}\right)
$$

Similarly the mass balance equations for insulin concentration are developed. Insulin is produced by pancreas proportional to plasma glucose concentration. When glucose level falls below the threshold insulin production is ceased.

$$
\left.\begin{array}{rlrl}
\text { Insulin production rate } & =0 & G \leq \phi \\
& =\varepsilon(G-\phi) & G>0
\end{array}\right\}
$$

Insulin is destroyed by the reaction of insulinase enzyme.

$$
\text { Insuin destruction rate }=\mathrm{QI}
$$

Combining the equations we get

$$
\left.\begin{array}{ll}
I=0 & \mathrm{Gs0} \\
=\frac{\varepsilon(\mathrm{G}-0)}{0} & \mathrm{0} 0
\end{array}\right)
$$


The steady state level of glucose and insulin under given set of conditions for diabetes can be predicted from this model by solving above equations.

The glucose and insulin values are plotted as shown in figure 2 , where $\mathrm{N}$ is the steady state point. This model contains strong non linearity in the form of product of $\mathrm{G}$ and $\mathrm{I}$ and thresholding non linearity. The non linear ties in this model are reduced by considering dynamic response. In this dynamic response linear techniques cannot be used. The non linearity can be reduced by replacing segments of hyperbolic with piece wise linear approximations. The obtained equations are extended to incorporate dynamics in the following way:

$$
\left.\begin{array}{l}
\mathrm{Cg} \frac{\mathrm{dG}}{\mathrm{dt}}=\mathrm{U}+\mathrm{Q}-8 \mathrm{G}-\mathrm{vGI} \\
\mathrm{eg} \frac{\mathrm{dG}}{\mathrm{dt}}=\mathrm{U}+\mathrm{Q}-8 \mathrm{G}-\mathrm{vGI}-\mu(\sigma-\alpha) G<a
\end{array}\right\}(8) .
$$

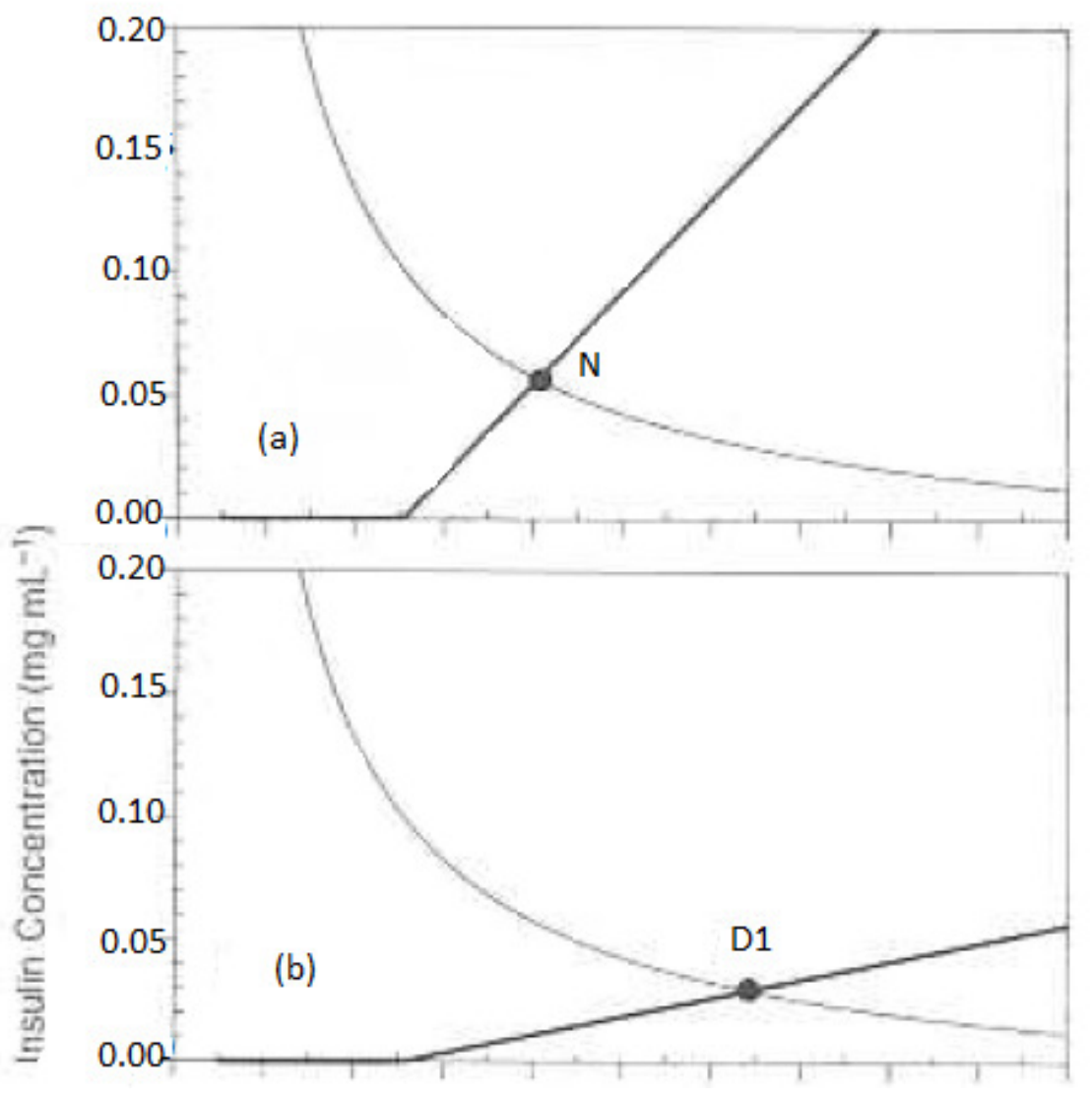




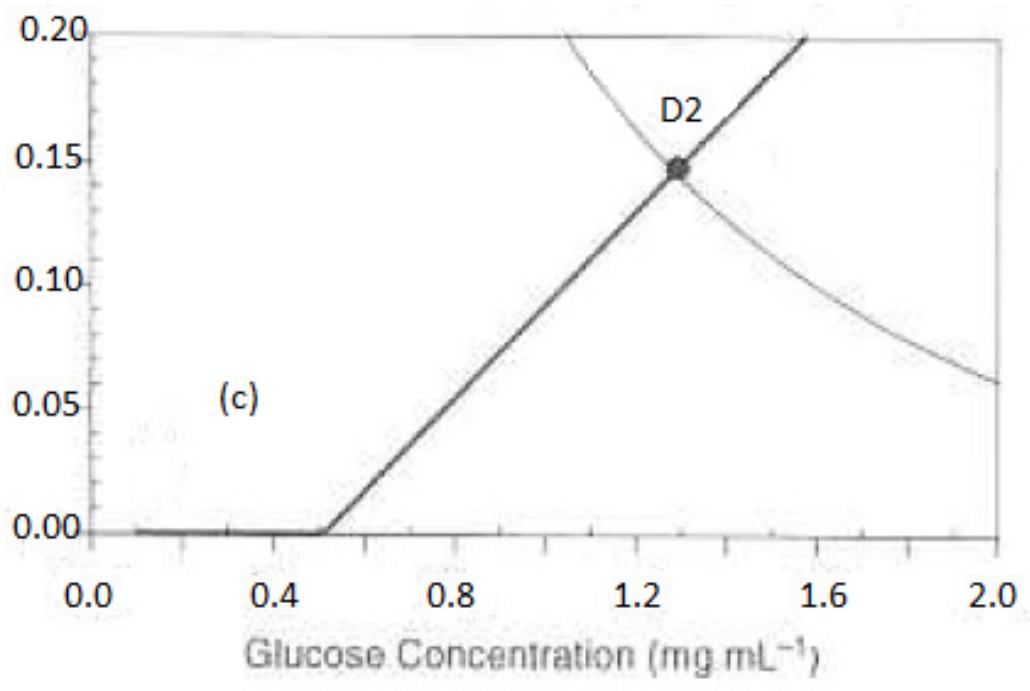

Figure2: Steady state analysis of glucose regulation (a) Normal person. (b) Type-1 Diabetic (c) Type-2 Diabetic

In Type-1 or Insulin dependent diabetes, the main defect is in the ability of the islet cells in the pancreas to produce required amount of insulin. We modelled this condition by lowering the sensitivity of the insulin response to glucose. The above figure 2 gives the effect of reducing the sensitivity to $20 \%$ of the normal value. From the above graph we observed the new steady state point D1. Type-2 diabetes is also referred to as non insulin dependent diabetes; we modelled this condition by changing the value of the parameter ' $v$ '. For new steady state value we decreased the value an amount of ' $v$ ' to $20 \%$ of its original value. The new equilibrium point is occurred at D2. Insulin equations are extended in the same way to incorporate dynamics.

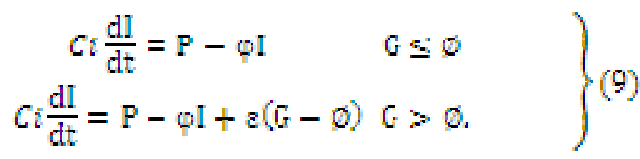

The parameters used in above equations are given below

$\mathrm{C}_{\mathrm{g}}=$ Glucose capacitance,

$\mathrm{C}_{\mathrm{i}}=$ Insulin capacitance,

$\mu, b_{2} \mathrm{v}=$ proportionality factors,

$\alpha=$ Reabsorption constant,

$\emptyset=$ Threshold glucose concentration,

$\mathrm{G}=$ Glucose concentration,

$\mathrm{I}=$ Insulin concentration.

$\mathrm{U}=$ Glucose infusion rate

$\mathrm{P}=$ External insulin infusion rate.

The parameter values given in the table 1 are for a healthy person and used in simulation. 
Table1: Parameter values

\begin{tabular}{|c|c|}
\hline PARAMETER & VALUE \\
\hline $\mathrm{Q}$ & $8400 \mathrm{mg} / \mathrm{h}$ \\
\hline$\mu$ & $7200 \mathrm{~mL} / \mathrm{h}$ \\
\hline$s$ & $1430 \mathrm{mUmL} / \mathrm{mgh}$ \\
\hline $\mathrm{V}$ & $2470 \mathrm{~mL} / \mathrm{h}$ \\
\hline$\Delta$ & $7600 \mathrm{~mL} / \mathrm{h}$ \\
\hline$\varphi$ & $2.5 \mathrm{mg} / \mathrm{Ml}$ \\
\hline $\mathrm{A}$ & $0.51 \mathrm{mg} / \mathrm{mL}$ \\
\hline$\varnothing$ & \\
\hline
\end{tabular}

\section{SIMULATION RESULTS}

The model is implemented in LABVIEW as shown in figure 3 and the input and output graphs for normal,type-1 and type-2 diabetic persons are shown in figures (4),(5),(6)and(7). In LABVIEW we use simulation loop to use the threshold operator and integrator block which are present in control design and simulation tool kit. In the front panel of LABVIEW we represent the food intake and glucose concentration and insulin concentration graphs where as in the back panel we implement the modelling equations obtained for a normal,type- 1 and type- 2 diabetic persons. The glucose and insulin concentration levels for normal person,Type- 1 and Type- 2 diabetic persons are simulated and results are tabulated in the Table 2. The glucose infusion rate is considered as step input. When the food is taken the glucose concentration is increased, resulting in the release of insulin. After a period glucose concentration reaches to its steady state value. And there after the insulin concentration also reaches to its steady state.

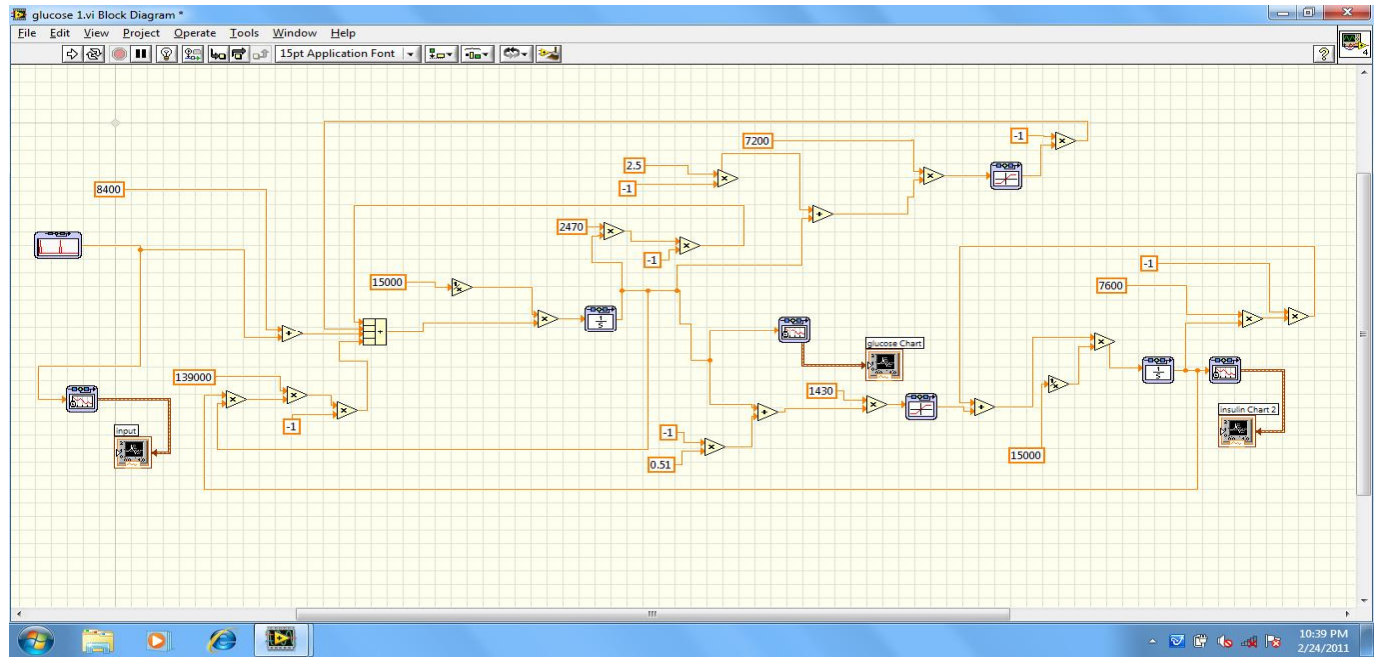

Figure.3: LABVIEW diagram 
International Journal of Instrumentation and Control Systems (IJICS) Vol.2, No.4, October 2012

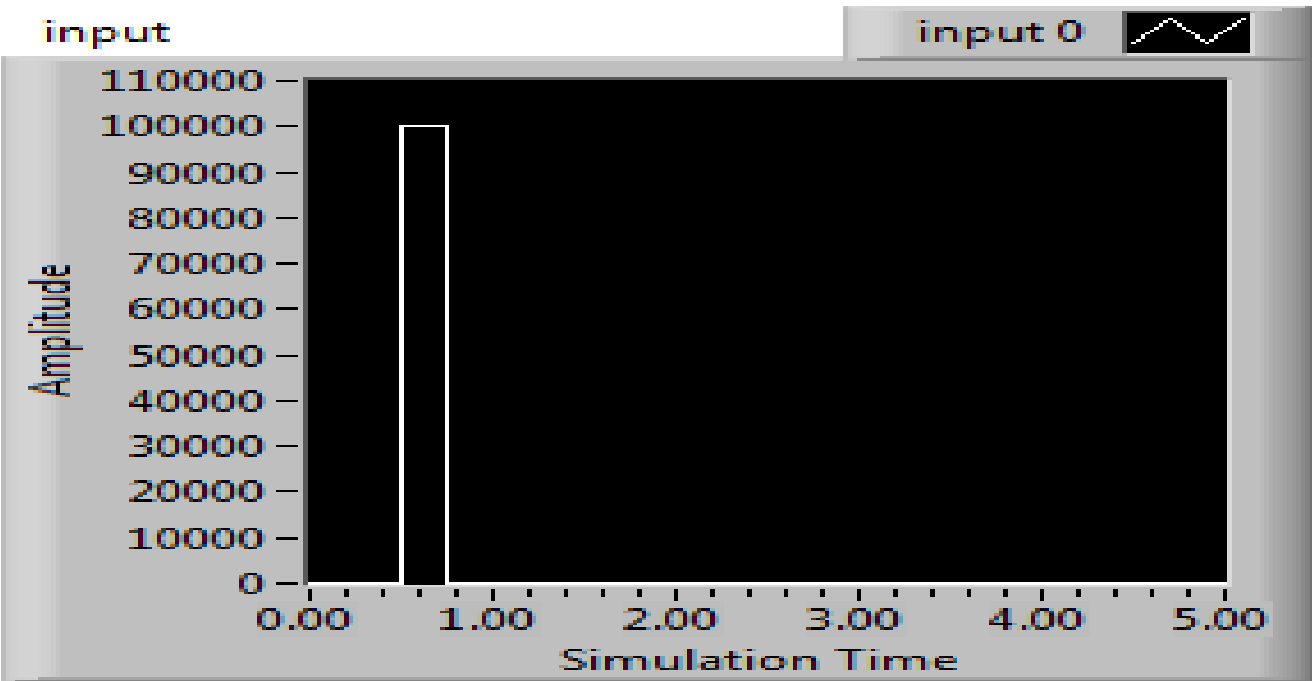

Figure.4: Glucose infusion rate curve for Normal,type-1 and type-2 diabetic persons

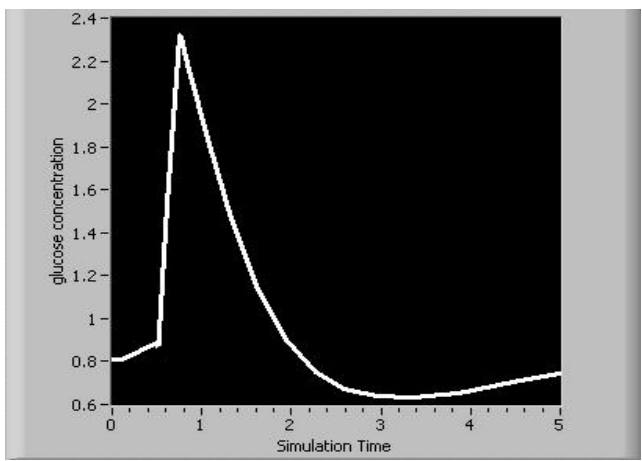

Figure 5(a) Glucose Concentration

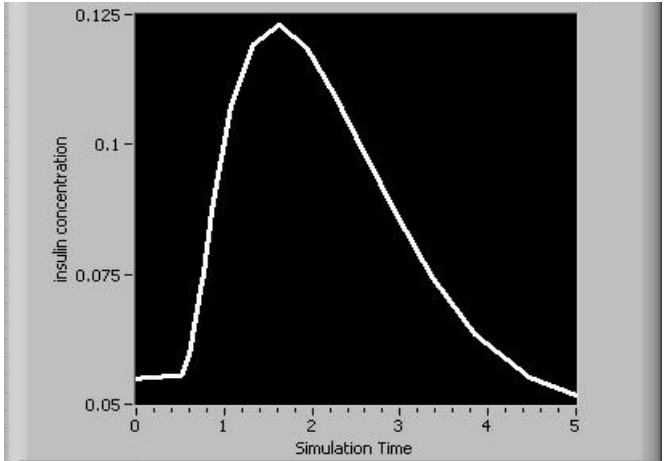

Figure 5(b) Insulin Concentration

Figure 5 Glucose and Insulin concentration curves $\left(\mathrm{mg} \mathrm{mL}^{-1}\right)$ for Normal person

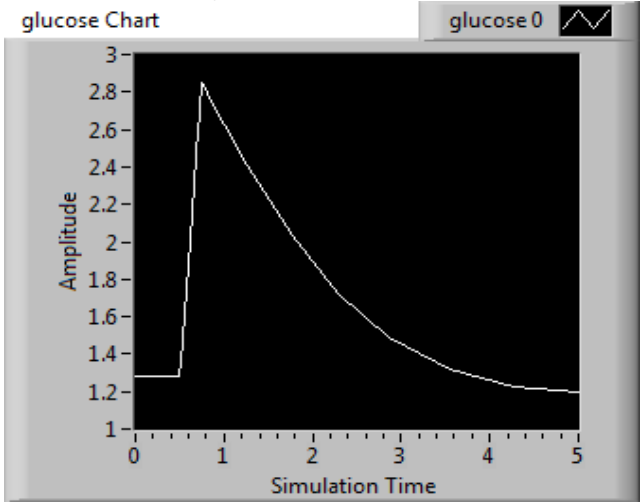

Figure 6(a) Glucose Concentration

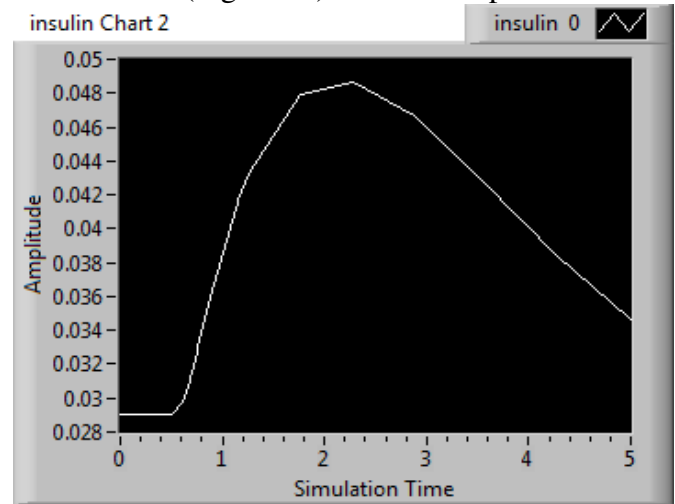

Figure 6(b) Insulin Concentration 
Figure 6 Glucose and Insulin concentration curves $\left(\mathrm{mg} \mathrm{mL}^{-1}\right)$ for type-1diabetic person

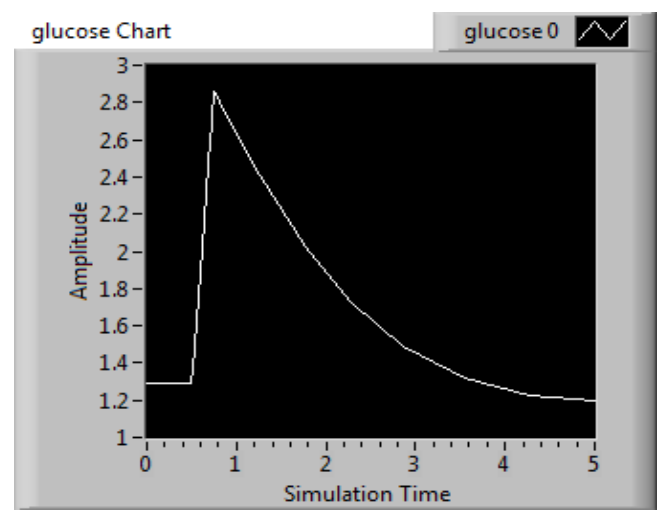

Figure 7(a) Glucose Concentration

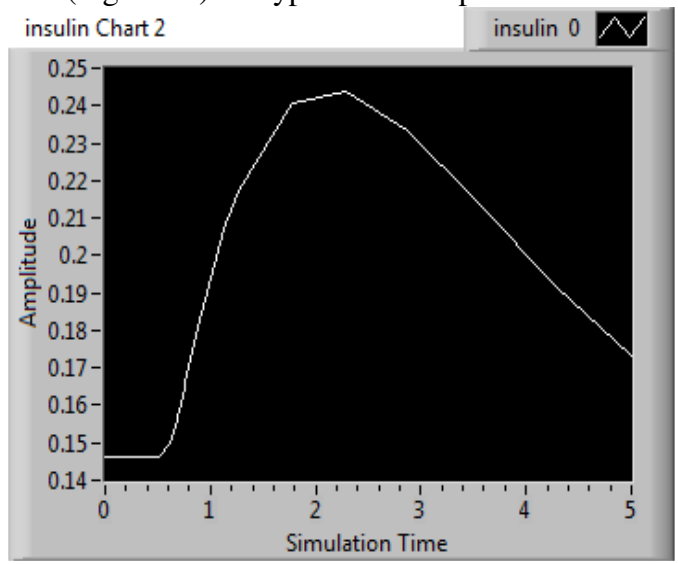

Figure 7(b) ) Insulin Concentration

Figure 7 Glucose and Insulin concentration curves $\left(\mathrm{mg} \mathrm{mL}^{-1}\right)$ for type-1diabetic person

\section{OBSERVATIONS}

The simulation results for normal, type- 1 and type- 2 diabetic persons are tabulated in table 2.Based on the simulation results tabulated in table 2 we observed that type- 1 diabetic person body produces very less amount of insulin compared to normal person. Consequently, excessive amounts of glucose accumulate in the blood. Even though the blood has plenty of insulin, the cells of a person with diabetes are not getting their crucial energy and growth requirements. Generally insulin pumps and inhaled insulin techniques are used for the administration of insulin in the treatment of type-1 diabetic patients. These simulation results are useful for the design of insulin pumps and other related medical equipment. Based on the simulation results we also observed that type-2 diabetic person body produces more insulin but glucose concentration is more compared to normal person. The body produces insulin, but its insulin sensitivity is undermined and does not work as it should do - glucose in not entering the body's cells properly. Consequently, blood sugar levels rise, and the cells are not getting their required nutrients for energy and growth. Treatment like Diet, exercise, weight loss, and in many cases medication are useful for type-2 diabetic persons. Insulin Injections may also be used in some cases and simulation results are useful for the selection of insulin concentration. 
Table 2: Glucose and insulin concentrations for Normal, Type-1 and Type-2 diabetic persons

\begin{tabular}{|c|c|c|c|c|c|c|c|}
\hline \multirow{2}{*}{$\begin{array}{l}\text { Simul- } \\
\text { ation }\end{array}$} & \multirow{2}{*}{$\begin{array}{c}\text { Food } \\
\text { Intake }\end{array}$} & \multicolumn{2}{|c|}{ Glucose concentration $\left(\mathrm{mg} \mathrm{mL}^{-1}\right)$} & \multicolumn{3}{|c|}{ Insulin concentration $\left(\mathrm{mg} \mathrm{mL}^{-1}\right)$} \\
\cline { 3 - 8 } & & $\begin{array}{c}\text { Normal } \\
\text { Person }\end{array}$ & $\begin{array}{c}\text { Type-1 } \\
\text { diabetes }\end{array}$ & $\begin{array}{c}\text { Type-2 } \\
\text { diabetes }\end{array}$ & $\begin{array}{c}\text { Normal } \\
\text { person }\end{array}$ & $\begin{array}{c}\text { Type-1 } \\
\text { diabetes }\end{array}$ & $\begin{array}{c}\text { Type-2 } \\
\text { diabetes }\end{array}$ \\
\hline 0.00 & 0.0000 & 0.815127 & 1.28005 & 1.29000 & 0.055000 & 0.0290000 & 0.14600 \\
\hline 0.50 & 0.0000 & 0.815127 & 1.28057 & 1.28999 & 0.055007 & 0.0290054 & 0.14600 \\
\hline 0.50 & 100000 & 0.815127 & 1.28236 & 1.28984 & 0.055086 & 0.0290054 & 0.14604 \\
\hline 0.75 & 100000 & 0.815127 & 1.28236 & 1.28925 & 0.055086 & 0.0290054 & 0.14615 \\
\hline 0.75 & 0.0000 & 0.815127 & 1.28236 & 1.28925 & 0.055086 & 0.0290054 & 0.14615 \\
\hline 0.86 & 0.0000 & 0.815127 & 1.28236 & 1.28925 & 0.055086 & 0.0289993 & 0.14615 \\
\hline 1.08 & 0.0000 & 2.321990 & 2.49713 & 1.29666 & 0.055448 & 0.0356048 & 0.16452 \\
\hline 1.32 & 0.0000 & 2.321990 & 2.56731 & 2.46134 & 0.073575 & 0.0411314 & 0.20860 \\
\hline 1.94 & 0.0000 & 2.321990 & 2.85088 & 2.49721 & 0.087351 & 0.0414854 & 0.20953 \\
\hline 2.27 & 0.0000 & 1.133750 & 2.02850 & 2.51693 & 0.123078 & 0.0479313 & 0.21721 \\
\hline 2.60 & 0.0000 & 1.133750 & 1.72279 & 2.02721 & 0.118659 & 0.0486250 & 0.24043 \\
\hline 2.95 & 0.0000 & 1.133750 & 1.48653 & 1.72111 & 0.109390 & 0.0466341 & 0.24365 \\
\hline 3.86 & 0.0000 & 0.674507 & 1.48653 & 1.48484 & 0.098460 & 0.0427914 & 0.23348 \\
\hline 4.47 & 0.0000 & 0.701678 & 1.32008 & 1.31860 & 0.063584 & 0.0383745 & 0.21409 \\
\hline 5.00 & 0.0000 & 0.745758 & 1.19403 & 1.19328 & 0.051694 & 0.0346433 & 0.17317 \\
\hline
\end{tabular}

\section{CONCLUSION}

A closed-loop model for Glucose- Insulin regulation has been designed, implemented and analyzed by using dynamic equation parameters for type- 1 and type- 2 diabetic persons by considering normal person dynamics as standard. This model is simulated with the help of LABVIEW. The proposed model show significant management and regulation of glucose insulin kinetics and useful for design of insulin pump and other related medical devices. We are confident that our model in LABVIEW can contribute in the research and subject fields. Glucose insulin regulation an absorbing and demanding area for research and the work could substantially be carried forward in the following directions as advancement:

1. Improvement of the mathematical model of insulin curve

2. Enhancement of efficiency and reliability of sensor in closed loop model

3. Biological compatibility of sensor, electro medical device and diabetic.

\section{REFERENCES}

[1] Pinky Dua, Francis J .Doyle, and Pistikopoulos, "Model-Based Blood Glucose Control for Type 1 Diabetes via Parametric Programming," IEEE Transactions on Biomedical Engineering, vol.53 pp.1478-1491, August 2006..

[2] Bolie, V.W., Coefficients of Normal Blood Glucose Regulation, Journal Of Applied Physiology, 16, 783, 1961.

[3] Ackerman, E., Gate wood, L.C., Rosevear, J. W. and Molnar, G.D., "Model studies of blood glucose regulation”, The Bulletan of Mathematical Bio Physics, 27(suttl.), 21,1965 
[4] Bergman, R.N., Philips, L.S and Cobelli, C., "Physiologic evaluation of factors controlling glucose tolerance in man", A Journal of clinical investigation, 68, 1456, 1981.

[5] Cobelli, C. and Ruggeri, A., "Evaluation of portal/peripheral route end of algorithms for insulin delivery in closed loop control of glucose in diabetes- A modelling study "IEEE transactions on Biomedical Engineering, BME-30: 90-103,1983.

[6] Lehmann, E.D. and Deutsch, T., "A Physiological Model of Glucose-Insulin Interaction in Type 1 Diabetes Mellitus", Journal of Biomedical Engineering, 14,

[7] Puckett, W.R, "Dynamic Modeling of Diabetes Mellitus" PhD. Dissertation, Department of Chemical Engineering, University of Wisconsin-Madison, 1992.

[8] Puckett, W.R and Lightfoot, E.N., "A Model for Multiple Subcutaneous Insulin Injections Developed from Individual Diabetic Patient data" American journal of Physiology,269(Endocrinology metabolism 32), E115,1995.

[9] Nicolas W. Chabat, Tuhin K. Roy "Glycemic Control in Critically Ill Patients - Effect of delay in Insulin Administration" Proceedings of the 2005 IEEE Engineering in Medicine and Biology 27th Annual Conference Shanghai, China, September 1-4, 2005.

[10] Zlatko Trajanoski, Paul Wach, "Neural Predictive Controller for Insulin Delivery Using the Subcutaneous Route" IEEE Transactions on Biomedical Engineering, vol.45, pp: 1122-1134, 1998.

[11] J.Geoffrey Chase, Z-H Lan, J-Y Lee, and K-S Hwang “Active Insulin Infusion of the Blood Glucose Derivative," Seventh International Conference on Control, Automation, pp.1162-1167, December 2002

[12] Jiming Chen, Kejie Cao, 1 You Xian Sun, Yang Xiao, and Xu (Kevin)Su, "Continuous Drug Infusion for Diabetes Therapy: A Closed-Loop Control System Design” Received 15 july 2007; Revised 25 November 2007; Accepted 5 December 2007.

[13] Dr. Jameel Ahmed, Dr. Bilal A. Alvi, Zeeshan Ali khan“Blood Glucose Insulin Regulation and Management System using MATLAB/SIMULINK" 2008 International Conference on Emerging Technologies. IEEE-ICET 2008, Rawalpindi, Pakistan, 18-19 October, 2008. 